Revista Brasileira de Meteorologia, v.25, n.2, 270 - 285, 2010

\title{
CRITÉRIOS DE ESTABILIDADE ATMOSFÉRICA PARA A REGIÃO DA CENTRAL NUCLEAR ALMIRANTE ÁLVARO ALBERTO, ANGRA DOS REIS - RJ
}

\author{
JOSÉ FRANCISCO DE OLIVEIRA JÚNIOR, LUIZ CLÁUDIO GOMES PIMENTEL, LUIZ LANDAU
}

\author{
Universidade Federal do Rio de Janeiro (UFRJ), Programa de Engenharia Civil (PEC/COPPE), Rio de \\ Janeiro - RJ, Brasil
}

jfoliverjr@lamma.ufrj.br, pimentel65@gmail.com, landau@lamce.ufrj.br

Recebido Agosto 2008 - Aceito Dezembro 2009

\begin{abstract}
RESUMO
Realizaram-se avaliações climatológicas, sazonais e diárias, da estabilidade atmosférica na região da Central Nuclear Almirante Álvaro Alberto (CNAAA), Angra dos Reis - RJ. A climatológica foi baseada no critério de Pasquill-Gifford (P-G) para um período de 26 anos (1980-2006) e a sazonal-diária pelos números de Richardson Global $\left(\mathrm{Ri}_{\mathrm{B}}\right)$ e de Froude $\left(\mathrm{F}_{\mathrm{r}}\right)$ - estudo de caso (2002-05). O $\mathrm{F}_{\mathrm{r}}$ foi usado na caracterização do escoamento da região. O critério de P-G mostrou que as classes predominantes foram D, E e F (no período noturno e diurno). Avaliaram-se as classes predominantes com a direção e velocidade do vento, os setores mais freqüentes foram S, SSW, SSE no período diurno e N, NNE, NNW e E no noturno. Quanto à velocidade verificou-se que a classe D foi mais veloz, e as classes $\mathrm{E}$ e $\mathrm{F}$ menos velozes, em qualquer período. As maiores velocidades foram coincidentes com a brisa marítima. Baseado no $\mathrm{Ri}_{\mathrm{B}}$, a condição estaticamente estável prevaleceu em comparação às demais, sendo de $79 \%$, seguida da instável (17\%) e neutra (4\%). O $\mathrm{F}_{\mathrm{r}}$ indicou que o escoamento na CNAAA foi caracterizado por regime de vento fraco, com forte estabilidade e ar estagnado. A maior parte das ocorrências (63\%) foi para $F_{r}$ inferior a 0,1, seguida de poucas ocorrências nas categorias $F_{r}$ igual a $1,0(8 \%)$ e superior a 1,7 (12\%). Os critérios utilizados na caracterização da estabilidade na região e na análise do regime de escoamento indicaram a baixa capacidade da atmosfera para a dispersão de poluentes, devido à predominância da condição estável e do regime de bloqueio.
\end{abstract}

Palavras-chaves: Central Nuclear, Escoamento local, Dispersão.

\begin{abstract}
CRITERIA OF ATMOSPHERIC STABILITY FOR THE REGION AROUND THE NUCLEAR POWER PLANT ALMIRANTE ÁLVARO ALBERTO, ANGRA DOS REIS -RJ

The atmospheric stability over the nuclear power plant Almirante Álvaro Alberto (CNAAA), Angra dos Reis - RJ, Brazil, was analyzed at climatological, seasonal, and daily scales. The climatologic analysis was based on the Pasquill-Gifford (P-G) for a long-term series of 26 years (1980 - 2006), while the seasonal/daily was performed using the Global Richardson number, $\mathrm{Ri}_{\mathrm{B}}$, and the Froude number, $\mathrm{F}_{\mathrm{r}}$, (case study 2002-2005). The Froude number was used for the regional flow characterization. According to the P-G criteria, the dominant classes were D, E and F (for diurnal and nocturnal periods). The most frequent sectors of wind direction were S, SSW, SSE in diurnal period and N, NNE, NNW and $\mathrm{E}$ in nocturnal. The highest wind velocities were observed for class $\mathrm{D}$ while the lowest values were observed for classes $\mathrm{E}$ and $\mathrm{F}$, for both periods. The highest wind velocities were correlated to the occurrence of sea breeze. Based on $\mathrm{Ri}_{\mathrm{B}}$, the dominant stratification regime was stable (for $79 \%$ of the time), followed by unstable (17\%) and neutral (4\%). According to $\mathrm{F}_{\mathrm{r}}$, the flow around CNAAA was characterized by low wind velocities, strong stability and stagnant air. The $\mathrm{F}_{\mathrm{r}}$ was lesser than 0.1 during $63 \%$ of the time, equal to 1 for $8 \%$ of the time and greater than 1.7 during $12 \%$ of the time. The criteria used in the determination of the stability and flow characteristics of this region indicated the lower dispersion capacity of the local atmosphere due to the prevalence of stable stratification regimes and blocking conditions.
\end{abstract}

Keywords: Nuclear Power Plant, Local flow, Dispersion. 


\section{INTRODUÇÃO}

A estabilidade da atmosfera é um dos fatores fundamentais para o estudo dos fenômenos de dispersão de efluentes e poluentes (Seinfield e Pandis, 2000). Os efeitos da estabilidade atmosférica têm sido intensivamente estudados nas últimas décadas, principalmente, nos esquemas numéricos utilizados nos atuais modelos de mesoescala (Holton, 1992) e nos vários tipos de classificação disponíveis na literatura (Mohan e Siddiq, 1998). Essas formulações apresentam restrições, que podem influenciar nos resultados de ambos, observacionais e numéricos, e com isso gerar avaliações e previsões discordantes das condições locais (Stull, 1991; Pielke, 2002). A classificação da estabilidade atmosférica é necessária para quantificar a capacidade de dispersão da atmosfera ambiente. Algumas classificações são usadas como rotinas nos Modelos de Qualidade do Ar (MQAr) e nos modelos convencionais Gaussianos (Seinfield e Pandis, 2000).

A estabilidade atmosférica pode ser dinâmica ou estática, sendo que ambas as classificações fornecem medidas incompletas da existência da turbulência em uma região. A estática não inclui os efeitos de cisalhamento, ao passo que a dinâmica não inclui o processo não-local (Stull, 1988). Por isso, na prática para se determinar se o fluido é turbulento, avaliase as duas classificações. Os critérios do gradiente vertical de temperatura pontencial $(\mathrm{d} \theta / \mathrm{dz})$ e temperatura do ar (dT/dz), quando isolados, não são considerados bom indicadores da turbulência, por não conter informação do cisalhamento do vento. Mas, podem ser usados na caracterização da estabilidade estática (Holton, 1992). Por isso, muitos estudos observacionais e numéricos utilizam o Número de Richardson e Froude $\left(\mathrm{F}_{\mathrm{r}}\right)$, que por sua vez pode ser associado a outros critérios, tais como, Monin-Obhukov, Classes de estabilidade de Pasquill-Gifford e outros na avaliação e prevenção de episódios de qualidade do ar em uma região (Kaimal e Finnigan, 1994).

Existem vários tipos de classificação, que são baseadas na disponibilidade de parâmetros e variáveis meteorológicas, e na avaliação de processos atmosféricos que ocorrem na baixa atmosfera, em particular na Camada Limite Atmosférica (CLA). A classificação de Pasquill é das mais utilizadas, e caracteriza as propriedades dispersivas da atmosfera (Pasquill, 1961). Ela foi reformulada, e passou a ser conhecida por Pasquill-Gifford (P-G), sendo aplicada na maioria dos estudos de poluentes, efluentes gasosos ou partículas sólidas. Foi amplamente testada, com resultados de experimentos de campo (Turner, 1961; 1964) e modelos numéricos (Pasquill, 1976), sendo rigorosa na microescala, e freqüentemente estendida na mesoescala. $\mathrm{O}$ critério de P-G, abrange seis classes (A-F), passando da instável a muito estável. Ela exige apenas rotina de dados, baseandose em condições meteorológicas (Mohan e Siddiq, 1998), tais como, a velocidade do vento, associada a insolação durante o dia ou a fração de cobertura de nuvens durante a noite (Pasquill, 1961). Suas vantagens consistem na fácil aplicabilidade e simplicidade de conceitos, enquanto que a desvantagem é a subjetividade.

Turner (1964) propôs outra classificação denominada de objetiva. Ela foi introduzida para minimizar as ambigüidades do critério de P-G e abrange sete classes de estabilidade numeradas de 1 a 7. Golder (1972) mostrou existir equivalência entre as classes de estabilidade de P-G e as de Turner. No entanto, verifica-se que a de Turner introduz uma classe intermediária, entre a ligeiramente estável e a neutra. Outro tipo de classificação foi proposta por DeMarrais (1978), ela permite obter as classes de P-G, a partir do gradiente vertical de temperatura.

Originalmente, a classificação $\mathrm{P}-\mathrm{G}$ foi proposta pela Bristish Meteorological Office, em 1958, e sendo depois publicada por Pasquill (1961); onde a estimativa usava o espalhamento angular da pluma $\left(\theta_{\mathrm{p}}\right)$ e a altura vertical de espalhamento $\left(\mathrm{z}_{\mathrm{p}}\right)$ como função da distância da fonte próxima a superfície (x). Gifford (1961) converteu esses parâmetros dentro de desvios-padrão da distribuição de concentração nas direções lateral $\left(\sigma_{\mathrm{y}}\right)$ e vertical $\left(\sigma_{\mathrm{z}}\right)$, respectivamente. Ainda, Gifford (1961) propôs a relação em escala logarítmica dos desvios-padrão em função da distância, sendo depois, denominado de curvas de dispersão de P-G. O critério de P-G possui base teórica e experimental, porém existem restrições envolvendo a rugosidade aerodinâmica da superfície $\left(\mathrm{z}_{0}\right)$, o tempo de amostragem e a distância, e o tipo de fonte e sua altura (Arya, 2000).

O esquema Brookhaven National Laboratory (BNL) foi baseado em mais de 15 anos de dados de difusão, usando traçadores passivos a $108 \mathrm{~m}$ de altura e alguns próximos à superfície rugosa, em Upton - New York (Slade, 1968; Arya, 2000). Os parâmetros de dispersão $\sigma_{\mathrm{y}} \mathrm{e} \sigma_{\mathrm{z}}$ foram determinados pela análise extensiva de medidas de concentração, estendo-se até $60 \mathrm{~km}$ de distância. $\mathrm{O}$ esquema possui apenas quatro classes de estabilidade (A, $B_{2}, B_{1}$, C e D), sendo originalmente proposto por Smith (1951) apud Arya (2000). A principal limitação é que a caracterização da difusão e da turbulência foi retirada de locais específicos e aplicada estritamente em condições sem o efeito da flutuabilidade acima da Camada Limite Superficial (CLS), (Arya, 2000). Em contraste aos experimentos de difusão, usando traçadores e sem o efeito da flutuabilidade, foram aplicados nos esquemas de dispersão P-G e BNL.

Carpenter (1971) avaliou 20 anos de dados do experimento do Tennessee Valley Authority (TVA), com medidas de concentração de $\mathrm{SO}_{2}$ em plumas provenientes de Centrais Nucleares e relacionados com parâmetros meteorológicos. Este esquema possui seis classes (A-F), baseado no gradiente de temperatura potencial médio $(\partial \bar{\theta} / \partial z$ ) da altura da pluma. O 
esquema TVA tem várias limitações. Para pequenas distâncias da ordem de 5 a $10 \mathrm{~m}$ da altura da fonte, os coeficientes de difusão horizontal $-\sigma_{\mathrm{y}}$ e vertical $-\sigma_{\mathrm{z}}$, recebem maior influencia dos efeitos da flutuabilidade e do entranhamento sobre o espalhamento da pluma, do que da turbulência no ambiente e, portanto, não pode ser aplicável em liberações sem ou com fraca flutuabilidade. A outra limitação é o uso de $\partial \bar{\theta} / \partial z$ da altura da pluma como índice de estabilidade, que não é medida adequada da capacidade de mistura da atmosfera. Todos os esquemas de classificação, citados anteriormente, dividem a estabilidade dentro quatro ou sete categorias.

A dispersão de poluentes é baseada no conceito de advecção, sendo dependente do escoamento atmosférico médio, e nos mecanismos de difusão turbulenta, devido às forçantes térmicas e/ou mecânicas (Stull, 1988). Estes processos dependem da interação entre os mecanismos que ocorrem na atmosfera, tais como, estratificação térmica e regime de vento; dos efeitos provocados pela topografia (levantamento orográfico e bloqueio atmosférico) e das taxas de emissões (Oke, 1992). A estratificação térmica da atmosfera condiciona principalmente a dispersão vertical dos poluentes, enquanto que o vento predomina nos padrões de transporte horizontal. A intensidade do vento indica a extensão da área atingida e a sua direção determina quais os locais mais afetados pelas emissões (Stull, 1991).

A estabilidade atmosférica é importante na caracterização das estimativas da dispersão local, a curto (acidente) e longo prazo, bem como na necessidade de se determinar o que passa com o efluente (termo fonte) liberado a partir das Centrais Nucleares. Estas análises seguem exigências baseadas em guias de segurança, em relatórios e nas normas técnicas propostas pelos principais órgãos regulatórios espalhados pelo mundo, por exemplo, o United States Nuclear Regulatory Commission (USNRC); a Environmental Protection Agency (EPA), a International Atomic Energy Agency (IAEA) e a Comissão Nacional de Energia Nuclear (CNEN).

Assim, a Central Nuclear Almirante Álvaro Alberto (CNAAA), em Angra dos Reis, RJ, localizada em uma região complexa sob os pontos de vista meteorológico, topográfico e geográfico, necessita de avaliações sobre a estabilidade atmosférica da região (Leão, 1998; Oliveira Junior et al., 2005). Outra necessidade é conhecer os fenômenos locais e suas interações, o que propiciou diversos estudos observacionais e de modelagem nas últimas décadas (Nicolli, 1986; Martano e Paschoa, 1997; Leão, 1998; Franco, 2005; e Oliveira Júnior, 2008). Na CNAAA, diversas características locais e de escala sinótica interferem no regime de circulação e na estabilidade atmosférica, por exemplo, a topografia, a interação oceanocontinente e a atuação de sistemas de mesoescala e sinóticos (Oliveira Junior et al., 2005).

Desde a fase da construção da unidade I na CNAAA, foram realizados alguns estudos de difusão atmosférica na região, por exemplo, os realizados por Nicolli $(1981,1982)$ demonstraram através de dois anos (1973-75) consecutivos de dados, que as classes mais freqüentes do critério de P-G foram A e D (diurno) e E e F (noturno). Enquanto que Biaggio (1982), usando também uma base similar de dados, mostrou que as classes mais freqüentes foram D, E e A (diurno), ao contrário de Nicolli que encontrou a classe $E$ nesse período, e no noturno as mais freqüentes foram E e F. Leão (1992) determinou a

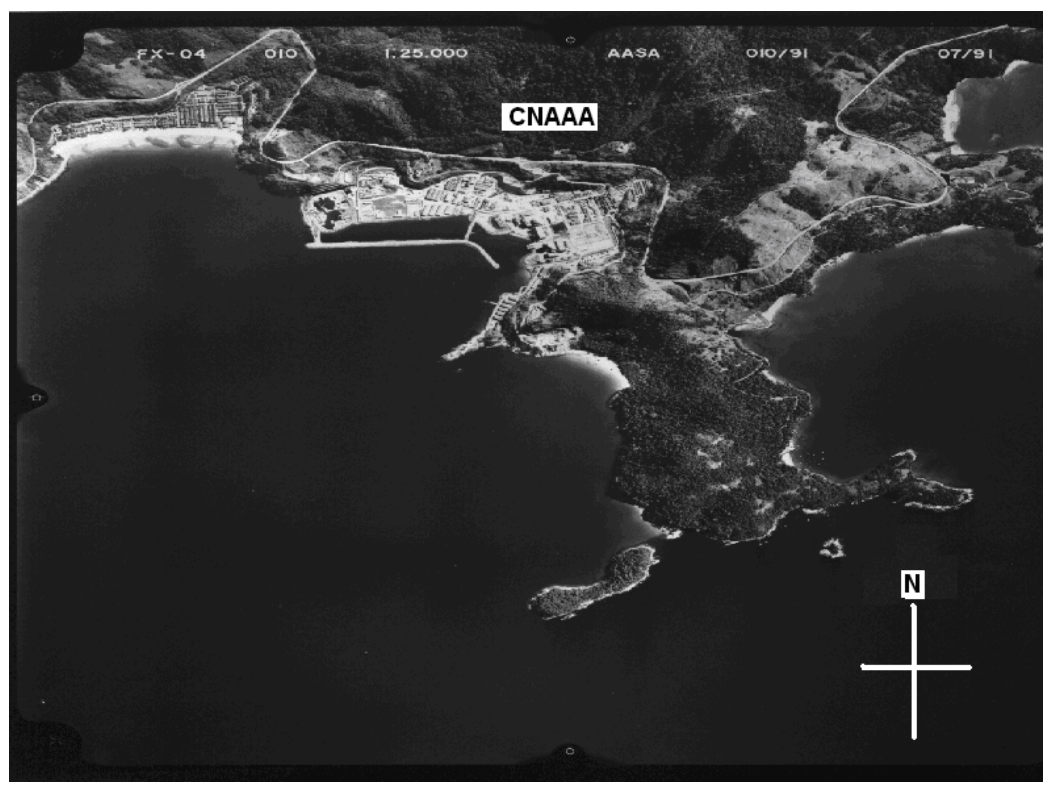

Figura 1 - Foto da região da CNAAA, destacando a topografia complexa e configuração da praia de Itaorna. Fonte: ELETRONUCLEAR 
freqüência da direção do vento por classe de estabilidade para cada setor na região, sendo as direções $\mathrm{N}$, NNE, NE associadas às classes $\mathrm{E}$ e $\mathrm{F}$, seguida das direções $\mathrm{S}$, WSW, W para a classe D. Anos mais tarde, Leão (1998) usando dados de 1992-96 determinou que a estabilidade na região tivesse padrão homogêneo para todas as estações do ano, e que as classes mais freqüentes foram D, E e F. Esses estudos, realizados anteriormente, se restringiram a períodos curtos de amostragem.

Baseado no exposto, o objetivo deste estudo é avaliar, climatologicamente e através de um estudo de caso, a estabilidade atmosférica e o regime do escoamento na região da CNAAA.

\section{DADOS E METODOLOGIA}

\subsection{Localização e Característica da Área de Estudo}

A área de estudo localizava-se em Angra dos Reis $\left(22,40^{\circ} \mathrm{S}, 44,30^{\circ} \mathrm{W}\right)$, litoral sul do Estado do Rio de Janeiro, tendo a extensão de $819 \mathrm{~km}^{2}$, distribuídos por $645 \mathrm{~km}^{2}$ de continente e $174 \mathrm{~km}^{2}$ de ilhas, onde se encontrava a CNAAA $\left(23,00^{\circ} \mathrm{S}, 44,28^{\circ} \mathrm{W}\right)$, (Figura 1$)$. A região da CNAAA possui orografia de altitude média, da ordem $700 \mathrm{~m}$, e dista $1 \mathrm{~km}$ do centro da área do vale. O nível do fundo do vale da CNAAA está entre 3 e 5 m acima do Nível Médio do Mar (NMM), e é aproximadamente retangular com área de $264.000 \mathrm{~m}^{2}$. As bordas orográficas são cortadas por paços de $125 \mathrm{~m}$ de elevação a $\mathrm{E}$ e de 100 m a S da área plana (Figura 2).

\subsection{Período de Estudo e Medidas Meteorológicas}

Os períodos avaliados neste estudo foram de 1980-2006 (climatologia), para o critério de P-G, e de 2002-2005 (estudo de caso) para os números de $\mathrm{Ri}_{\mathrm{B}}$ e de $\mathrm{F}_{\mathrm{r}}$. Foram utilizados medidas obtidas em uma torre meteorológica (A-10, 60 e 100 m) instalada na região que circunda a CNAAA (Tabela 1).

As variáveis e os parâmetros meteorológicos foram registrados em intervalos horários, sendo eles: velocidade (u, m/s) e direção (dir, ) do vento e temperatura do ar (T, C).

Foram desenvolvidos programas computacionais nas linguagens VISUAL-BASIC e FORTRAN (pré-processadores) para analisar as freqüências climatológicas, sazonais e diárias do escoamento e da estabilidade na CNAAA. Esta última escala temporal foi divida em quatro períodos: madrugada - 0-6 h; manhã - 6-12 h, tarde - 12-18 h e noite 18-24 h. O ADELTA2 consistia em um programa em FORTRAN, que realizava a extração do cadastro de dados meteorológicos da CNAAA. Este cadastro contém dados de direção e velocidade do vento, temperatura do ar, diferencial de temperatura para o três níveis da torre A (FURNAS, 1985).

A calmaria é toda situação na qual a velocidade do vento está abaixo da velocidade de partida do sensor. Como a velocidade de partida dos sensores na CNAAA é 0,36 m/s, no cadastro de dados meteorológicos só constam velocidades acima desta ou nulas (FURNAS, 1985), sendo adotadas nesse estudo. Foram consideradas as seguintes classes de velocidade do vento, conforme a Tabela 2. A classificação do setor conforme ângulo

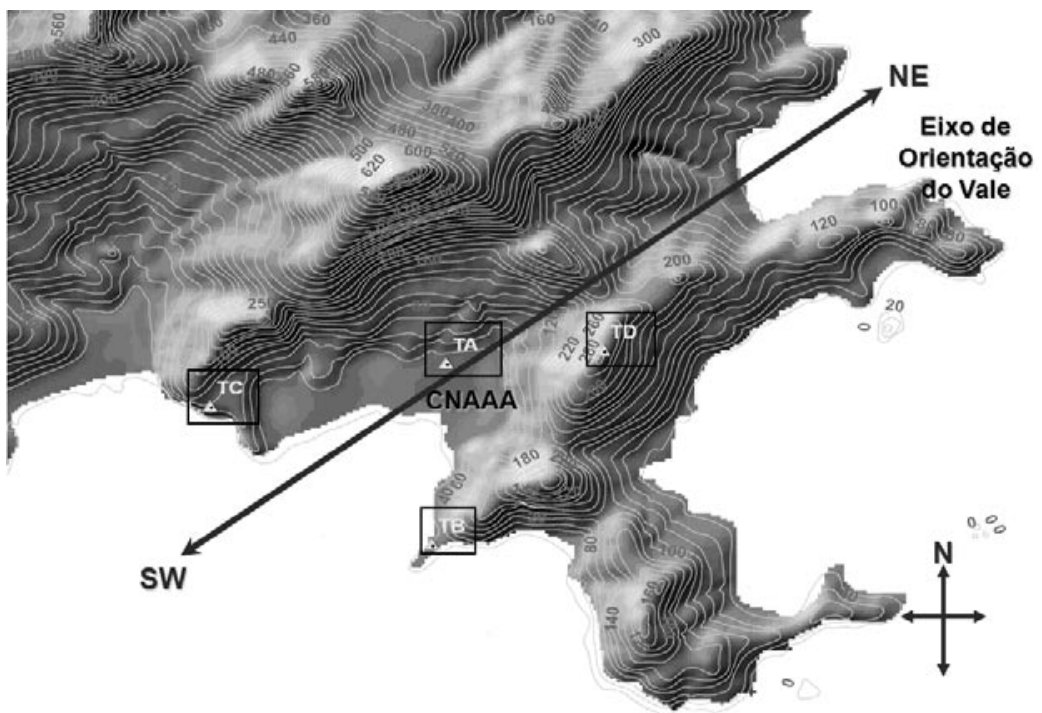

Figura 2 - Mapa topográfico de cota (m) do vale da CNAAA, com a respectiva localização das torres meteorológicas (TA, TB, TC e TD) e o eixo de orientação do vale.

Fonte: CPRM 
Tabela 1 - A torre meteorológica (A) existente na CNAAA, com suas respectivas altitude e alturas das medidas, coordenadas geográficas e variáveis meteorológicas.

\begin{tabular}{|c|c|c|c|c|c|}
\hline Torre A & $\begin{array}{l}\text { Coordenadas } \\
\text { geográficas } \\
\text { (lat. e lon.) }\end{array}$ & $\begin{array}{c}\text { Altitude da } \\
\text { base da } \\
\text { Torre } \\
\text { (NMM) } \\
\end{array}$ & $\begin{array}{l}\text { Distância com } \\
\text { referência a } \\
\text { Torre A }\end{array}$ & $\begin{array}{l}\text { Altitude das } \\
\text { medidas (m) }\end{array}$ & $\begin{array}{c}\text { Variáveis } \\
\text { meteorológicas }\end{array}$ \\
\hline A10 & $\begin{array}{l}23^{\circ} 00^{\prime} 19^{\prime \prime} \mathrm{S} \\
44^{\circ} 27^{\prime} 30^{\prime \prime} \mathrm{W}\end{array}$ & $50 \mathrm{~m}$ & 0 & $60 \mathrm{~m}$ & $\begin{array}{c}\mathrm{u}(\mathrm{m} / \mathrm{s}), \operatorname{dir}\left({ }^{\circ}\right) \mathrm{eT} \\
\left({ }^{\circ} \mathrm{C}\right),\end{array}$ \\
\hline A60 & $\begin{array}{l}23^{\circ} 00^{\prime} 19^{\prime \prime} \mathrm{S} \\
44^{\circ} 27^{\prime} 30^{\prime \prime} \mathrm{W}\end{array}$ & $50 \mathrm{~m}$ & 0 & $110 \mathrm{~m}$ & $\begin{array}{c}\mathrm{u}(\mathrm{m} / \mathrm{s}), \operatorname{dir}\left({ }^{\circ}\right) \mathrm{eT} \\
\left({ }^{\circ} \mathrm{C}\right),\end{array}$ \\
\hline $\mathbf{A 1 0 0}$ & $\begin{array}{l}23^{\circ} 00^{\prime} 19^{\prime \prime} \mathrm{S} \\
44^{\circ} 27^{\prime} 30^{\prime \prime} \mathrm{W}\end{array}$ & $50 \mathrm{~m}$ & 0 & $150 \mathrm{~m}$ & $\begin{array}{c}\mathrm{u}(\mathrm{m} / \mathrm{s}), \operatorname{dir}\left({ }^{\circ}\right) \mathrm{eT} \\
\left({ }^{\circ} \mathrm{C}\right),\end{array}$ \\
\hline
\end{tabular}

Tabela 2 - Classes de velocidade do vento e a faixa (m/s), conforme o programa ADELTA-2. Fonte: (FURNAS, 1985).

\begin{tabular}{c|c}
\hline Classe de Velocidade & $\begin{array}{c}\text { Faixa } \\
(\mathrm{m} / \mathrm{s})\end{array}$ \\
\hline 1 & $0,36 \leq \mathrm{u} \leq-0,50$ \\
\hline 2 & $0,51<\mathrm{u} \leq \mathbf{0 , 7 5}$ \\
\hline 3 & $0,76<\mathrm{u} \leq 1,0$ \\
\hline 4 & $1,1<\mathrm{u} \leq 1,5$ \\
\hline 5 & $1,6<\mathrm{u} \leq \mathbf{2 , 0}$ \\
\hline 6 & $2,1<\mathrm{u} \leq \mathbf{3 , 0}$ \\
\hline 7 & $3,1<\mathrm{u} \leq \mathbf{5 , 0}$ \\
\hline 8 & $5,1<\mathrm{u} \leq 7,0$ \\
\hline 9 & $7,1<\mathrm{u} \leq 10$ \\
\hline 10 (Calmaria) & $0 \leq \mathrm{u}<0,36$ \\
\hline
\end{tabular}

de direção do vento foi de 16 seções $\left(12,25^{\circ}\right)$, e as medidas foram obtidas entre as alturas 10 e $100 \mathrm{~m}$.

Basicamente, o programa foi usado para avaliar a distribuição de freqüência de ventos associada à rosa-dosventos, velocidade média, calmaria, separação por períodos (diurno, noturno e 24 horas) e a estabilidade local, esta baseada na relação entre o gradiente de temperatura e as classes de P-G (Tabela 3). No ADELTA-2 adotou-se a seguinte conceituação: período diurno (7 e 18 horas) e noturno (19 às 6 horas).

Realizaram-se, também, quantificações dos parâmetros temperatura potencial, $\mathrm{Ri}_{\mathrm{B}}$ e $\mathrm{F}_{\mathrm{r}}$ para avaliação do padrão da estabilidade e do regime de escoamento na CNAAA.

A temperatura potencial $(\theta)$ foi determinada pela relação:

$$
\theta=T+\left(\frac{g}{c_{p}}\right) z
$$

em que, $\mathrm{C}_{\mathrm{p}}\left(\mathrm{MJ} \mathrm{kg}{ }^{-1} \mathrm{~K}^{-1}\right)$ é calor específico à pressão constante, $\mathrm{g}\left(\mathrm{m} . \mathrm{s}^{-2}\right)$ é aceleração da gravidade, $\mathrm{T}(\mathrm{K})$ é a temperatura do ar, z (m) é altura de referência (as alturas 10 e $100 \mathrm{~m}$ ) e g/cp representa a razão adiabática seca $\left(9,8 \times 10^{-3} \mathrm{~K} \mathrm{~m}^{-1}\right)$

Dispondo de dados em três níveis na torre $\mathrm{A}$, optou-se pela utilização de um número aproximado de $\mathrm{Ri}_{\mathrm{B}}$, dado por:

$$
R_{i_{B}}=\frac{g}{T_{0}} \frac{\Delta \theta \Delta z}{(\Delta U)^{2}}
$$


em que, $\Delta z(\mathrm{~m})$ é a variação das alturas de medidas na torre $\mathrm{A}$, entre 10 e $100 \mathrm{~m}, \mathrm{~g} / \mathrm{T}_{0}\left(\mathrm{~m} \cdot \mathrm{s}^{-2} \cdot \mathrm{K}^{-1}\right)$ é parâmetro de flutuabilidade, $\Delta \theta(\mathrm{K})$ é a variação da temperatura potencial e $\Delta \mathrm{U}(\mathrm{m} / \mathrm{s})$ é a variação da velocidade do vento.

$\mathrm{O}$ cálculo de $\mathrm{F}_{\mathrm{r}}$ foi feito pela Equação 3:

$$
F_{r}=\frac{U}{N H}
$$

onde:

$$
N=\left(\frac{g}{\theta_{0}} \frac{\partial \theta}{\partial z}\right)^{1 / 2} \ldots \ldots . . . \frac{\partial \theta}{\partial z}=\frac{\Delta T}{\Delta z}+\Gamma
$$

Em que, $\mathrm{U}(\mathrm{m} / \mathrm{s})$ é a velocidade do escoamento, $\mathrm{N}\left(\mathrm{s}^{-1}\right)$ é a freqüência de Brunt-Vaisälä, $\theta(\mathrm{K})$ é a temperatura potencial, $\Delta \mathrm{T} / \Delta \mathrm{z}\left(\mathrm{K} \cdot \mathrm{m}^{-1}\right)$ é diferencial de temperatura, $\Gamma\left(9,8 \times 10^{-3} \mathrm{~K} \cdot \mathrm{m}^{-}\right.$ $\left.{ }^{1}\right)$ é taxa adiabática seca e $H(m)$ é a altura média da cadeia montanhosa da CNAAA. O F $F_{\mathrm{r}}$ obedeceu à classificação baseada no critério adotado por Stull (1988), (Tabela 4).

A estabilidade atmosférica e o escoamento na CNAAA foram plotadas na forma de histogramas de freqüência relativa.

\section{RESULTADOS}

\subsection{Caracterização Climática da Estabilidade Atmosférica 1980-2006}

\subsubsection{Critério de Pasquill-Gifford (P-G)}

Durante o período de estudo, as classes de estabilidade de P-G (Tabela 3) predominantes foram E, F e D (Figura 3a), o que indicou a ocorrência na região de condicionamento estaticamente estável ou neutro, em ambos os períodos noturno e diurno. No período diurno, 28\% dos casos ocorreram para a classe $\mathrm{D}$, enquanto que no noturno a ocorrência dessa classe de estabilidade foi de apenas 4\%. As maiores ocorrências no período diurno foram provavelmente devido à maior geração de turbulência por efeitos mecânicos durante o dia, provocados principalmente pela circulação da brisa marítima na região (Oliveira Júnior, 2008). A classe E apresentou as maiores freqüências nos dois períodos, sendo que $75 \%$ dos casos durante a noite e 59\% no período diurno. Esses resultados implicam em predominância de condições desfavoráveis à dispersão de poluentes na região da CNAAA. Para o regime de calmaria, observou-se também padrão similar (Figura 3b). Verificou-se, através de análises complementares (Figura não mostrada) que as classes E e F ocorrem em horários preferenciais entre o final da tarde e início da manhã (entre 17 até 7 h), devido ao resfriamento radiativo da superfície da região.

A condição de estabilidade atmosférica é importante também para a circulação da brisa marítima. Verificou-se que situações instáveis (A e C) ocorreram no período diurno, e representaram 1\% das observações, sendo favoráveis ao desenvolvimento, entrada e atuação da circulação da brisa marítima na região, ao contrário de estudo realizado anteriormente, onde a classe A foi a mais freqüente (Biaggio, 1982). O forte regime estável observado na região pode inibir o potencial desenvolvimento vertical da circulação da brisa marítima, o que a deixaria rasa na CNAAA. O efeito da brisa marítima junto à costa, freqüentemente, começa no fim da

Tabela 3 - Critério de estabilidade atmosférica local baseada nas classes de Pasquill-Gifford, conforme o programa ADELTA-2.

\begin{tabular}{|c|c|c|}
\hline $\begin{array}{l}\text { Número de } \\
\text { Froude }\left(\mathrm{F}_{\mathrm{r}}\right)\end{array}$ & Situação Atmosférica & Características \\
\hline $\mathbf{F}_{\mathbf{r}}=\mathbf{0 , 1}$ & Vento Fraco e Forte Estabilidade & $\begin{array}{c}\text { O escoamento é bloqueado e torna-se } \\
\text { estagnado. }\end{array}$ \\
\hline$F_{r}=0,4$ & $\begin{array}{l}\text { Vento Moderado e Fraca } \\
\text { Estabilidade }\end{array}$ & $\begin{array}{l}\text { Parte do escoamento percorre a montanha } \\
\text { e o restante sobre ela. E o ar no topo da } \\
\text { montanha é perturbado ocorrendo à } \\
\text { formação das Lee waves. }\end{array}$ \\
\hline $\mathbf{F}_{\mathbf{r}}=\mathbf{1 , 0}$ & Vento Forte e Fraca Estabilidade & $\begin{array}{l}\text { Ocorrência de comprimento de onda } \\
\text { natural maior que a profundidade da } \\
\text { montanha. As Lee waves tornam-se mais } \\
\text { intensas e o ar em superfície estagnado. }\end{array}$ \\
\hline $\mathbf{F}_{\mathbf{r}}=\mathbf{1}, 7$ & $\begin{array}{l}\text { Ventos Intensos e Fraca } \\
\text { Estabilidade }\end{array}$ & $\begin{array}{l}\text { O comprimento de onda natural é maior } \\
\text { que a profundidade da montanha. Ocorre a } \\
\text { separação da CLA a sotavento da } \\
\text { montanha, e cria-se uma região de } \\
\text { cavidade com direção do vento contrária } \\
\text { em superfície. }\end{array}$ \\
\hline
\end{tabular}
Fonte: (FURNAS, 1985). 

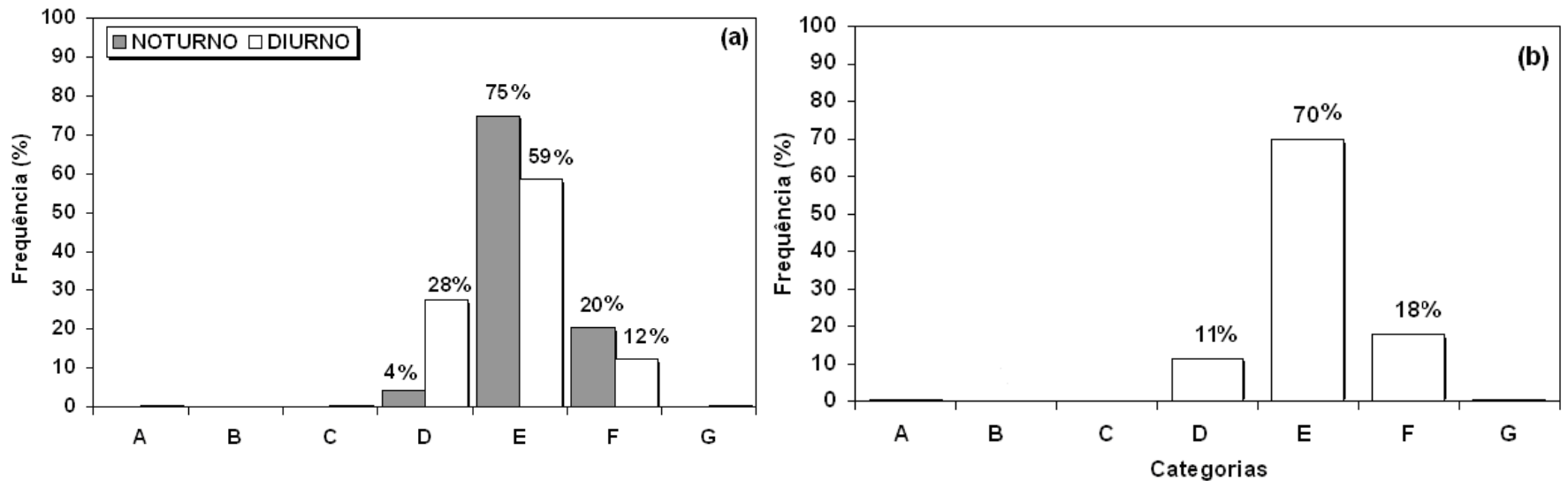

Figura 3 - Freqüência (\%) das classes de estabilidade de Pasquill-Gifford, durante o regime (a) diurno (7 até 18 horas), noturno (19 até 6 horas) e da calmaria (b) na CNAAA (1980-2006).
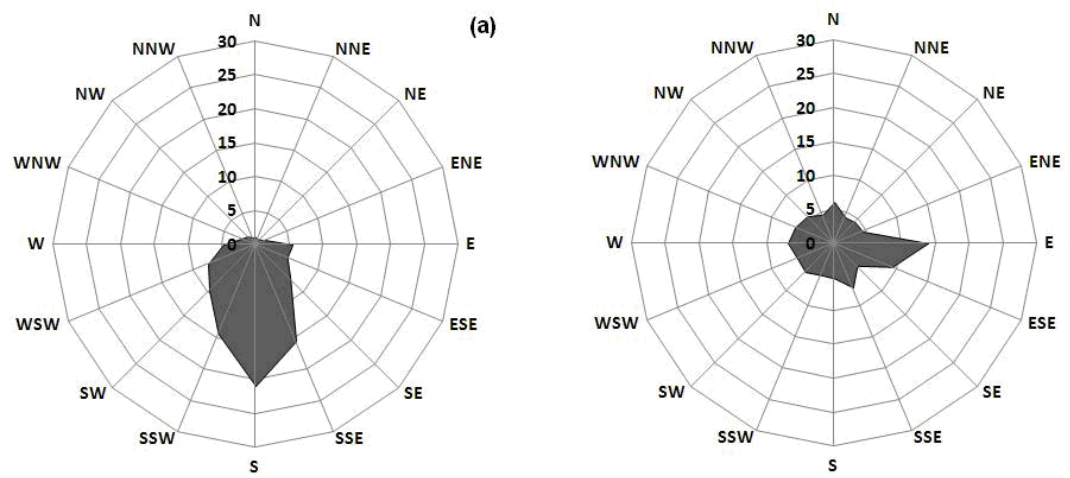

(d)
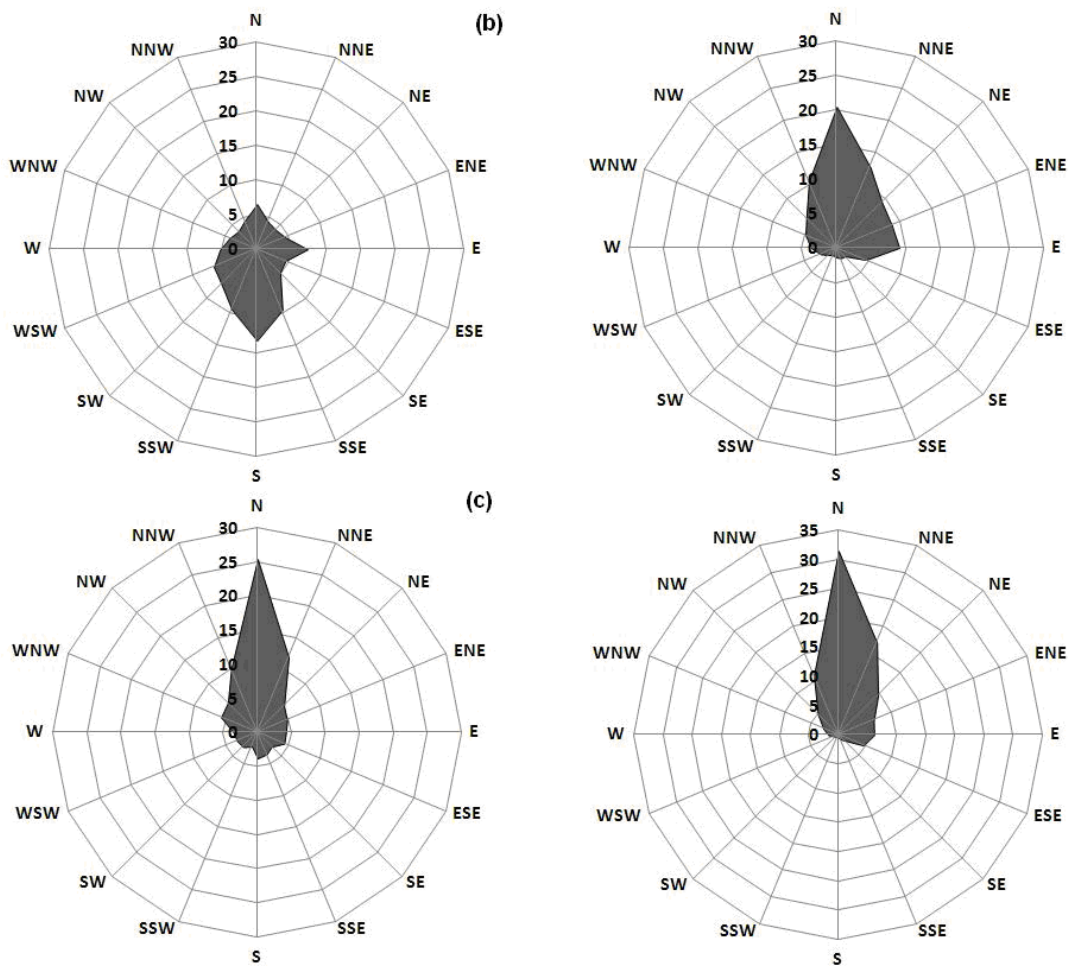

(e)

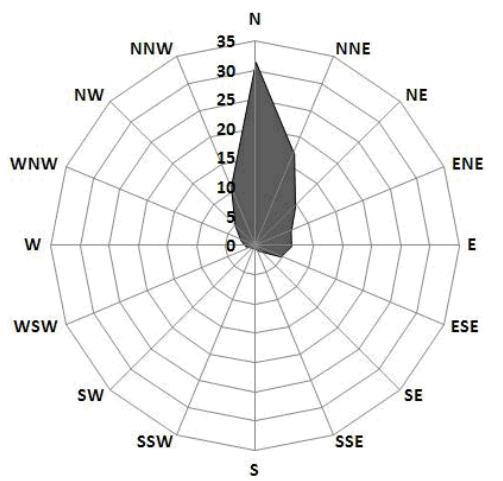

(f)

Figura 4 - Freqüência (\%) da direção do vento $\left(^{\circ}\right.$ ) versus as classes de estabilidade D (a-d), E (b-e) e F (c-d) nos regime diurno (a, b e c) e noturno (d, e e f) da Torre A-CNAAA (1980-2006). 
manhã, e atinge seu máximo no início da tarde e desaparece ao anoitecer, enquanto que as brisas terrestres, em geral, são menos intensas do que as marítimas (Oke, 1992). Porém, a brisa marítima na CNAAA permanece atuando até algumas horas da noite, acopladas ao regime de vento de encosta (Figura não mostrada). Basicamente, a sua entrada e intensificação possuem horários preferenciais, entre as 10 e 11 h (início) e as 17 e $18 \mathrm{~h}$ (maturação), esses horários estão condicionados ao regime de estabilidade atmosférica na região.

\subsubsection{Classes de Estabilidade e Direção e Velocidade do vento}

Após a avaliação da estabilidade local pelo critério de P-G, mostrou-se que as predominâncias foram nas classes E, F e D, a partir disso avaliaram-se estas classes de estabilidade com a direção e velocidade do vento.
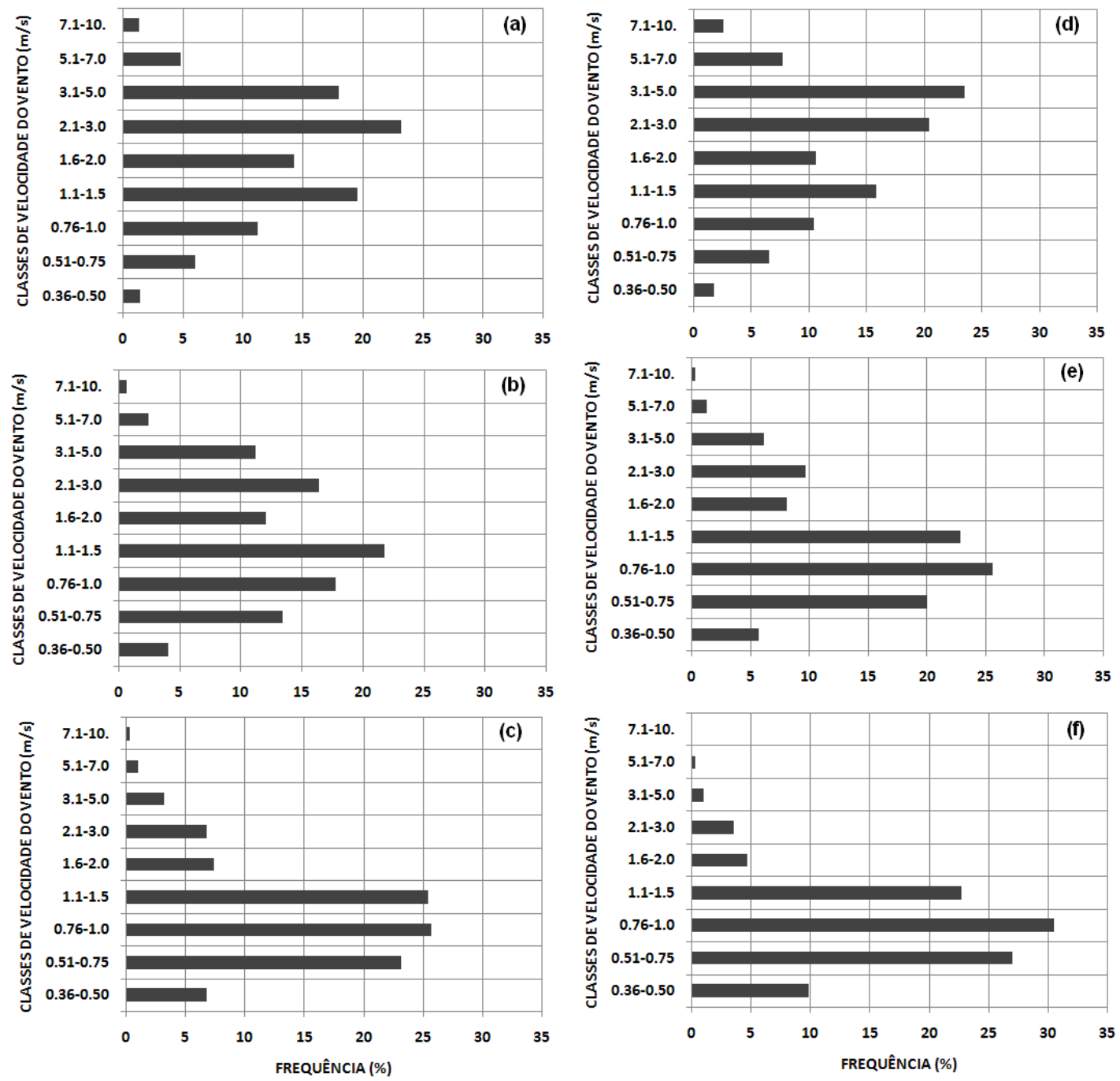
(1992), exceto a direção WSW (Classe D).
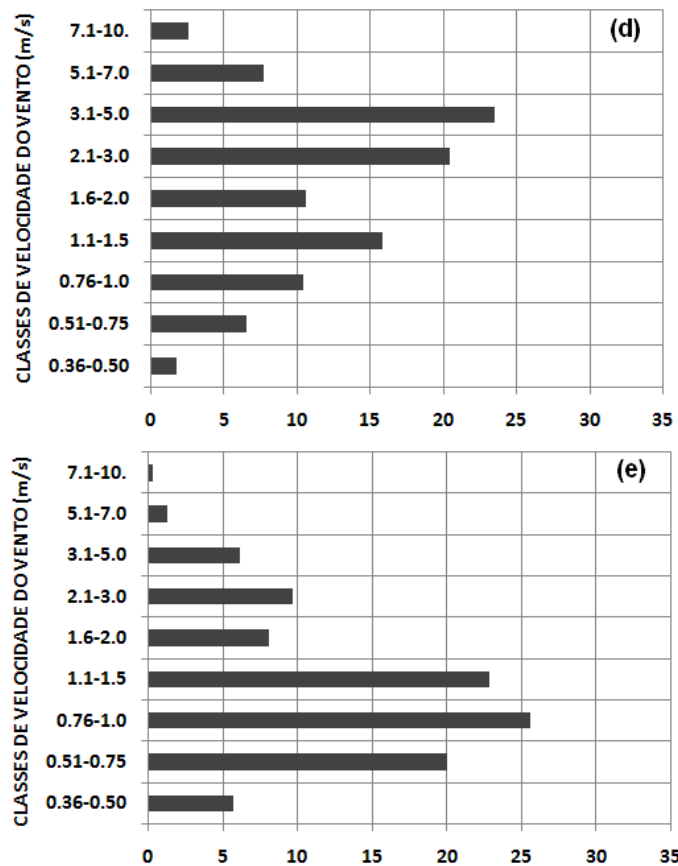

Figura 5 - Freqüência (\%) da velocidade do vento (m/s) versus as classes de estabilidade D (a-d), E (b-e) e F (c-d) nos regime diurno (a, b e c) e noturno (d, e e f) da Torre A-CNAAA (1980-2006).

As principais freqüências da classe D basicamente se concentraram nas direções SSE, S e SSW, durante o dia, isso devido à influência da circulação da brisa marítima na região, enquanto que à noite ocorreu diminuição significativa destas direções, sobressaindo-se as direções E e ESE, seguida de freqüências menores nas outras demais (Figuras 4a e 4d). A classe E, durante o dia, apresentou uma redistribuição nos setores N, E e W, porém a maior freqüência foi na direção S (Figura 4b), enquanto que à noite os maiores valores foram na direção $\mathrm{N}$ e NNE, coincidindo com os maiores paços topográficos $\mathrm{N}$ E e NNW (Figura 2). Esse resultado indicou a influência da topografia e do efeito costeiro no regime de estabilidade da CNAAA (Figura 4e). A direção $\mathrm{N}$ foi predominante na classe $\mathrm{F}$, independente do período, seguida de freqüências menores nas direções NNE e NNW (Figuras 4c e 4f). Os resultados encontrados nesse estudo concordaram com os obtidos por Leão 
Nas classes de velocidade observou-se que durante o dia foi bastante variado, (Figuras 5a), principalmente para classe D, onde a maior classe de velocidade foi de 2,1 - 3,0 m/s, seguida de menores ocorrências observadas nas classes de 1,1-1,5 e 3,1 $-5,0 \mathrm{~m} / \mathrm{s}$, essas ocorrências estão associadas a ventos fracos e a circulação da brisa marítima na região, porém durante a noite ocorreu aumento significativo da classe 3,1-5,0 m/s (Figuras 5d). Esse aumento mostra claramente o acoplamento da brisa marítima com regime de vento de encosta na CNAAA, citado anteriormente. Na classe $\mathrm{E}$ verificou-se bastante variadas as classes de velocidade durante o dia, porém com freqüência elevada de calmaria durante a noite (Figuras 5 b e $5 e$ ). Na classe F há a predominância de calmaria e ventos fracos (Figuras 5c e 5f). O que indicou que a proximidade da costa associada com a topografia complexa produz baixa velocidade do vento na CNAAA. Na eventualidade de acidente e liberação de material na atmosfera é fundamental o conhecimento do campo de vento envolvendo as condições de difusão e transporte sendo, portanto, o período da noite inadequado para liberação, exceto quando do acoplamento da brisa marítima e do vento de encosta, enquanto condições favoráveis são observadas durante o dia, quando da ocorrência da brisa marítima local.

Depois de verificada a predominância dos seguintes setores: N, NNE, NNW, S, SSW, SSE e E, realizou-se uma análise de como os setores contribuíram no espalhamento de poluentes na CNAAA.

Observou-se que a classe predominante foi a $D$ nas direções S, SSE e SSW, exceto na direção N, onde as predominâncias foram as classes E e F (Figura 6b), durante o dia, e uma segunda predominância foi a classe E. Isso mostrou permanência deste regime, mesmo no período diurno, e o aumento de $\mathrm{D}$, referese à influência da circulação da brisa marítima (Figura 6).
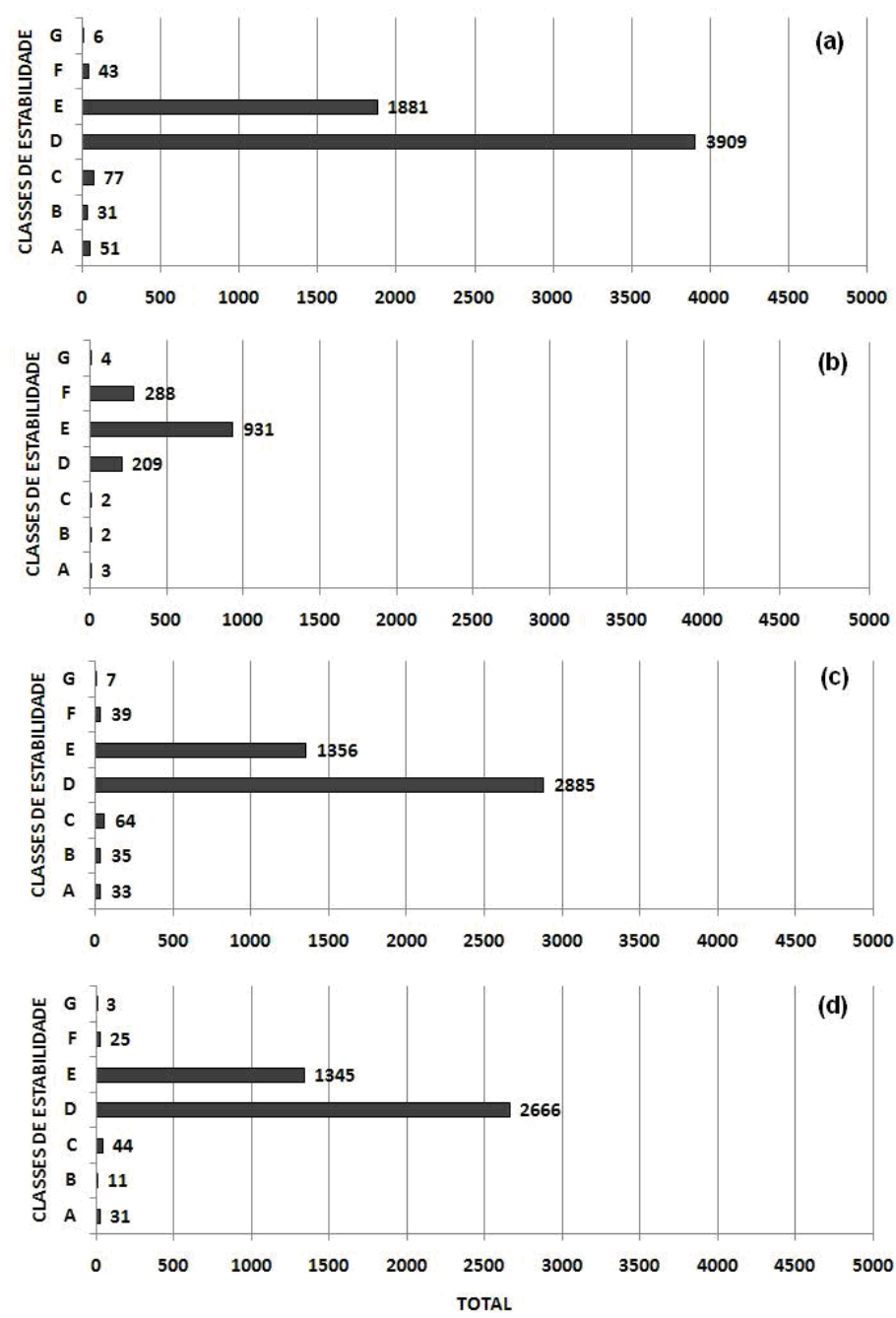

Figura 6 - Distribuição total (diurno) da direção do vento versus as classes de estabilidade de P-G para as seguintes direções: S (a), N (b), SSE (c) e SSW (d) (1980-2006). 
Notou-se que os valores no regime noturno estão associados com as cotas da cadeia montanhosa (regime de vento de encosta), o que faz com que mude a direção do vento e aumento considerável na classe E, seguida das classes $\mathrm{F}$ e D (Figura 7). Os menores valores estavam associados com a abertura da CNAAA para o Oceano Atlântico. A classe predominante foi a E nas direções N, NNE, NNW e E, durante a noite, uma segunda predominância foi à classe $F$, exceto na direção $\mathrm{E}$, onde a segunda predominância foi à classe $\mathrm{D}$. Isso mostra que a CNAAA à noite tem forte regime estável, isso pode ser atribuído a atuação conjunta do regime de vento de encosta e a formação da Camada Limite Noturna (CLN) no fundo do vale. Outro fato é que durante a noite apresentou- se um regime variado da velocidade na sua totalidade, com classe predominante de $1,1-1,5 \mathrm{~m} / \mathrm{s}$, exceto uma segunda predominância na classe $3,1-5,0 \mathrm{~m} / \mathrm{s}$. Porém, em média as maiores velocidades encontraram-se no fundo do vale e não próximas à cadeia montanhosa, confirmando assim o acoplamento entre esses distintos escoamentos.

\subsection{Estudo de Caso 2002 - 2005}

\subsubsection{Número de Richardson Global $\left(\mathbf{R i}_{B}\right)$}

A avaliação do condicionamento da estabilidade atmosférica na CNAAA pelo $\mathrm{Ri}_{\mathrm{B}}$ mostrou que a condição estável
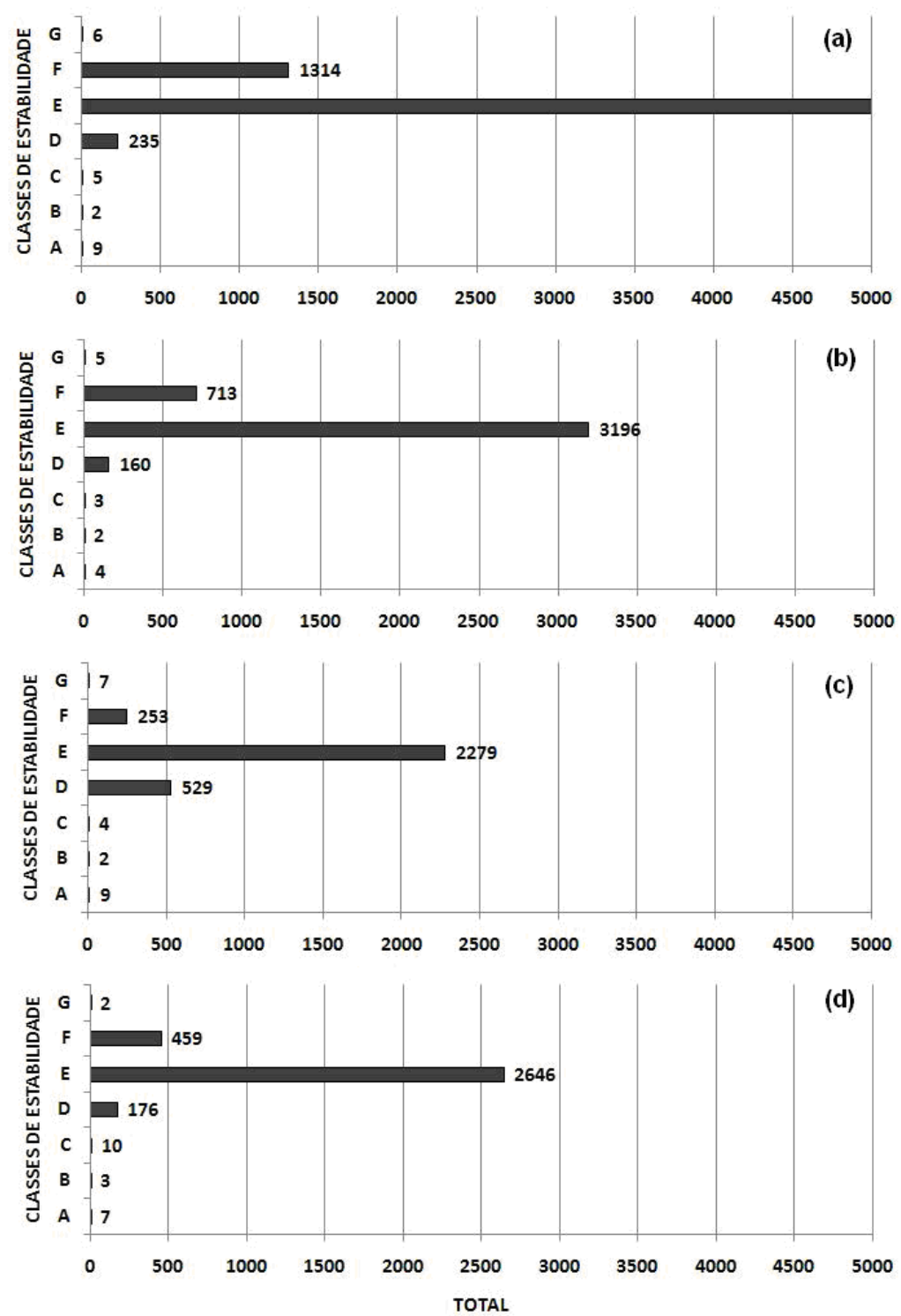

Figura 7 - Distribuição total (noturno) da direção do vento versus as classes de estabilidade de P-G para as seguintes direções: N (a), NNE (b), E (c) e NNW (d) (1980-2006). 
prevaleceu em comparação às demais, sendo as freqüências: de 79\% (estaticamente estável), seguida de 17\% (estaticamente instável) e 4\% (neutra), (Figura 8).

No período da madrugada (0-6 h), manhã (6-12 h) e a noite (18-24 h) houve predominância da condição estável independente da estação do ano (Figura 9). Essa ocorrência se deve a uma série de fatores, entre eles: ao gradiente vertical de temperatura, a variação da velocidade do vento e a mudança de $\mathrm{z}_{0}$ local. Durante a madrugada (Figura 9a), notou-se baixa amplitude sazonal (<3\%) da freqüência de ocorrências das situações estáveis. Destaca-se que no período da manhã (Figura 9b) e à noite (Figura 9d), ocorreu variação desse regime em função da estação do ano. Essa amplitude sazonal foi em torno de $10 \%$ nos períodos, sendo significativa quando comparado às freqüências observadas de no máximo 30\% (Figura 9).
No período da tarde (12-18 h) (Figura 9c), observou-se distribuição mais homogênea dos regimes estável e instável, em relação aos demais períodos (madrugada, manhã e noite), principalmente no verão e primavera. De qualquer modo, a condição instável sobressaiu-se no verão e na primavera, enquanto no outono e inverno, a estável teve maior freqüência de ocorrências.

Durante a manhã, devido ao aquecimento iniciou-se a distribuição das ocorrências estáveis entre os demais regimes, principalmente para instável, o que pode ser atribuído ao decaimento da Camada Limite Residual (CLR) e a formação da Camada de Mistura (CM) neste período. No período noturno há ocorrência de Camada de Inversão (CI), que se forma na CNAAA, e esta permanece até início da manhã. No início da noite, quando o saldo de radiação é negativo, a CLA não

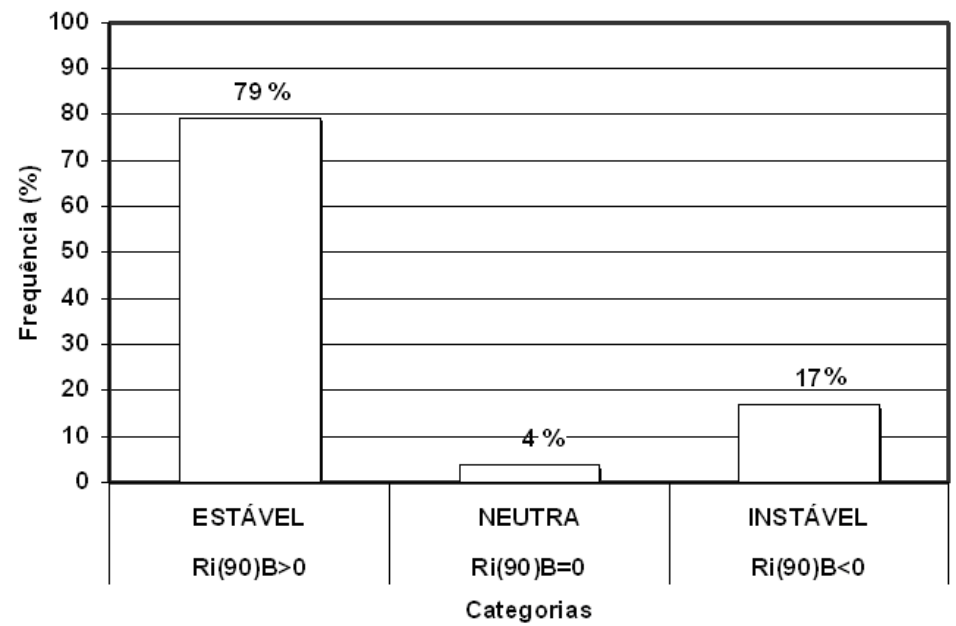

Figura 8 - Freqüência (\%) total do Número de Richardson Global (90 m) na Torre A (2002-2005).
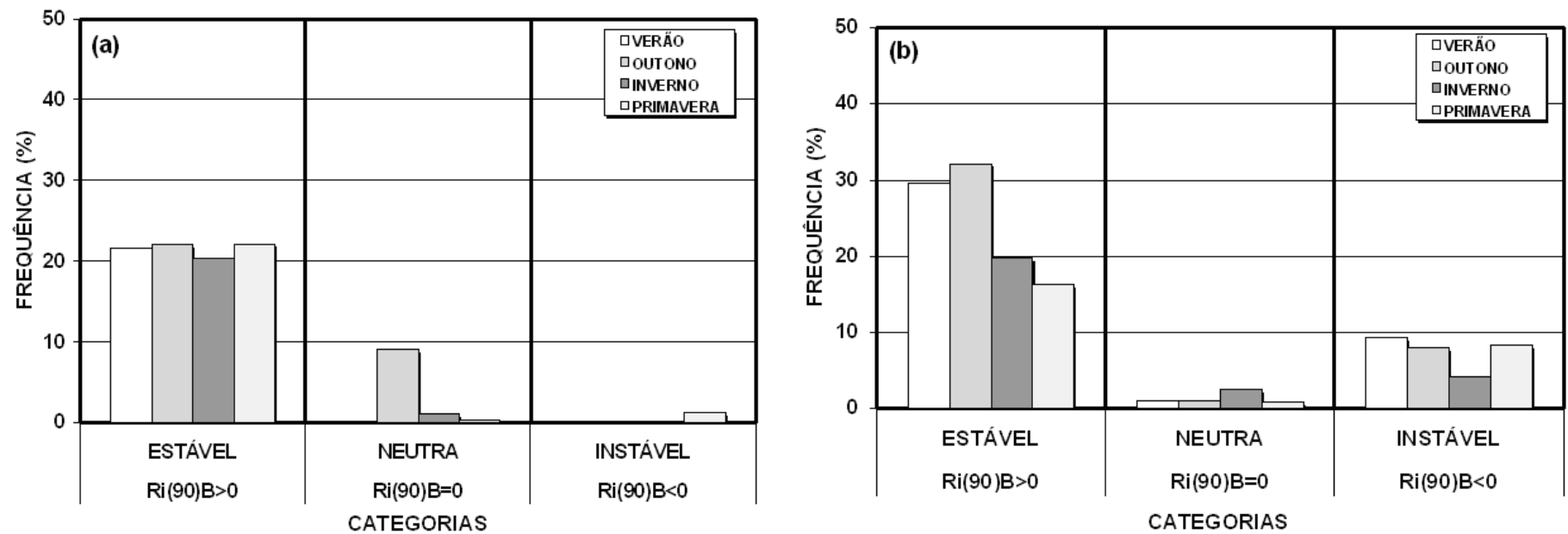

Figura 9 - Freqüência (\%) do Número de Richardson médio (90 m) sazonal - horária (a) 0-6, (b) 6-12 horas da Torre A (2002-2005). 

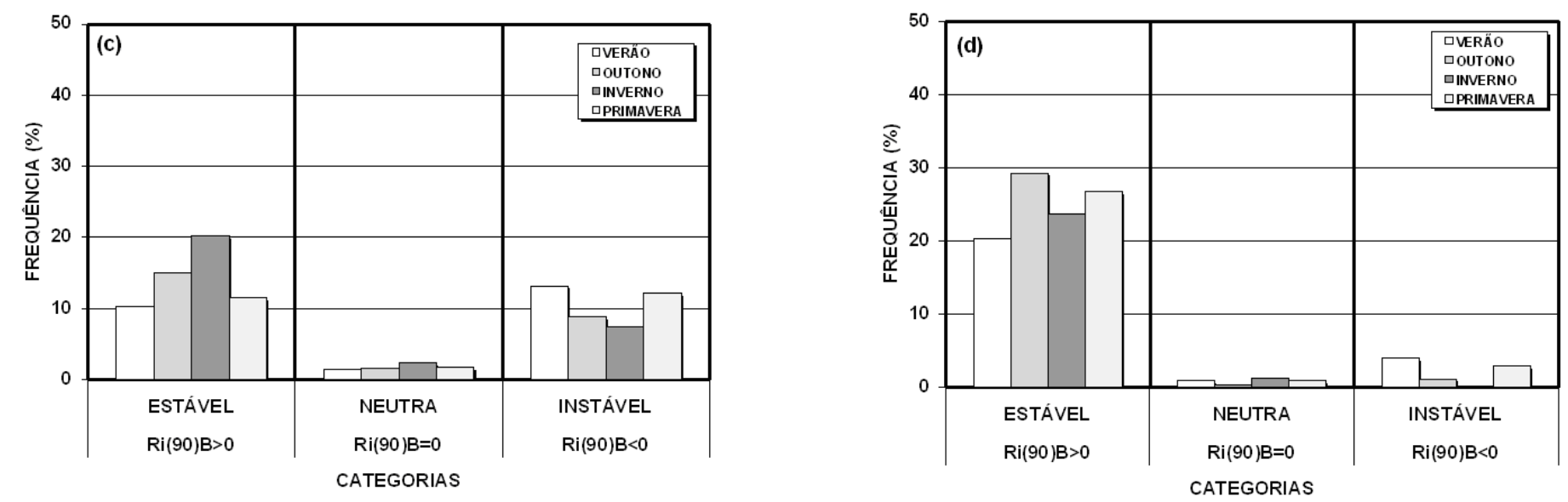

Figura 9: Freqüência (\%) do Número de Richardson médio (90 m) sazonal - horária (c) 12-18 e (d) 18 -24 horas da Torre A (2002-2005).

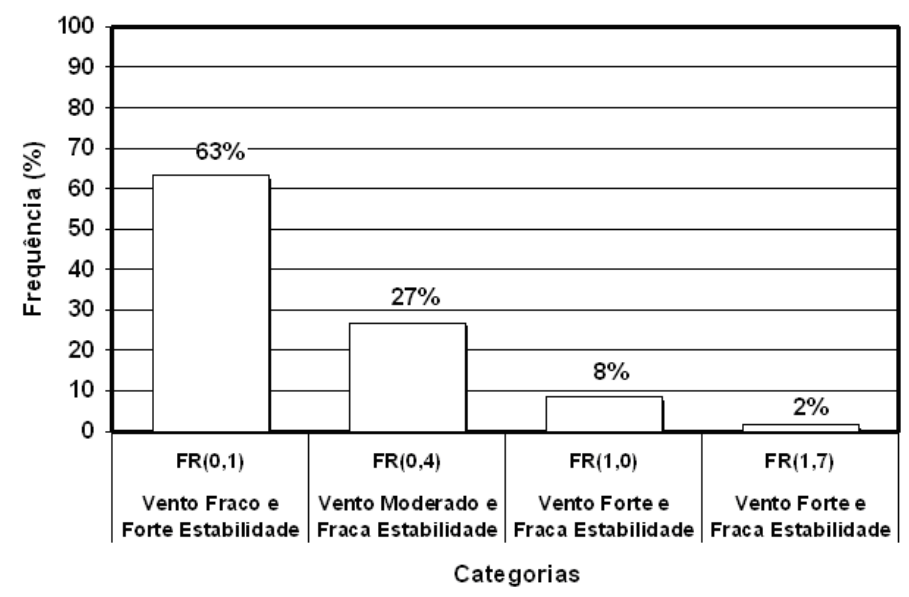

Figura 10 - Freqüência (\%) total do Número de Froude (100 m) na Torre A (2002-2005).

apresenta mais a influência dos processos turbulentos da maneira que ocorreram durante o dia. A partir disso, ocorre a formação da CI, causando um desacoplamento entre a superfície e a camada de mistura acima dela. A camada logo acima desta é a CLR, possuindo ainda as mesmas características da CLA desenvolvida ao longo do dia, sendo menos turbulenta (Stull, 1988). Antes do pôr do sol, as térmicas associadas à turbulência térmica, que são responsáveis pela mistura deixam de atuar. A CLR apresenta as mesmas variáveis médias de estado e de concentração da até então $\mathrm{CM}$. Esta camada possui estratificação neutra e a turbulência existente apresenta intensidade aproximadamente igual em todas as direções, com taxas de dispersão iguais tanto na vertical como na horizontal (Kaimal e Finnigan, 1994).

As comparações de $\mathrm{Ri}_{\mathrm{B}}$ médio mostraram diferenças significativas em relação à sazonalidade - diária, principalmente no verão e primavera nos períodos da manhã e tarde, com um aumento da condição instável. Observaram-se diferenças sazonais significativas das freqüências de $\mathrm{Ri}_{\mathrm{B}}$ associadas às classes de estabilidade, em todas as estações. Isto pode estar relacionado a processos de mistura turbulenta (manhã e tarde), associados à ocorrência de brisa marítima na CNAAA, que são qualitativamente diferentes em ambas as estações. Quando predomina o efeito do resfriamento radiativo (madrugada e noite), a condição estável volta a ser predominante.

\subsubsection{Número de Froude}

Basicamente, o escoamento próximo a Torre A, baseado no número de Froude (Tabela 4), apresentou situação de bloqueio e estagnação do ar na região da CNAAA, com as 
maiores ocorrências, cerca de $63 \%$, na categoria $F_{r}=0,1$, seguida de $27 \%$ para $\mathrm{F}_{\mathrm{r}}=0,4$ (Figura 10 ). Em geral, observou-se que a região possui regime de vento fraco, com forte estabilidade e ar estagnado, exceto para algumas ocorrências nas categorias $\mathrm{F}_{\mathrm{r}}=1,0(8 \%)$ e 1,7 (2\%).

No período da madrugada (Figura 11a) houve maior percentual do $\mathrm{F}_{\mathrm{r}}(0,1)-17 \%$, resultado similar foi observado no período da manhã (13\%) (Figura 11b) e durante a noite (12\%) (Figura 11d), com as maiores ocorrências na categoria $\mathrm{F}_{\mathrm{r}}(0,1)$. No período da tarde (Figura 11c), o padrão diferiu dos demais períodos, onde em termos percentuais as categorias $F_{r}$ $(0,1)$ e $F_{r}(0,4)$ se assemelham, e ainda ocorreu distribuição nas demais categorias. Essa redistribuição significativa neste período de ambas as categorias, se deve à influência conjunta da circulação da brisa marítima com a topografia da região. A categoria $\mathrm{F}_{\mathrm{r}}(0,4)$ aumentou sua freqüência à tarde, e permaneceu durante a noite, isso pode ter ocorrido devido ao acoplamento do regime de vento de encosta e o início e estágio maduro da

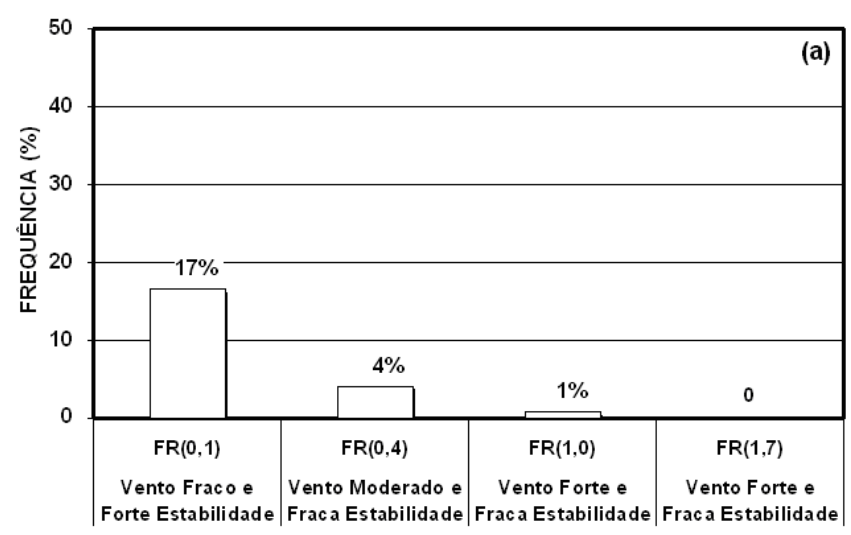

Figura 11 - Freqüência (\%) do Número de Froude (100 m) médio - horário (a) 0-6, (b) 6-12 horas da Torre A (2002-2005). Continuação

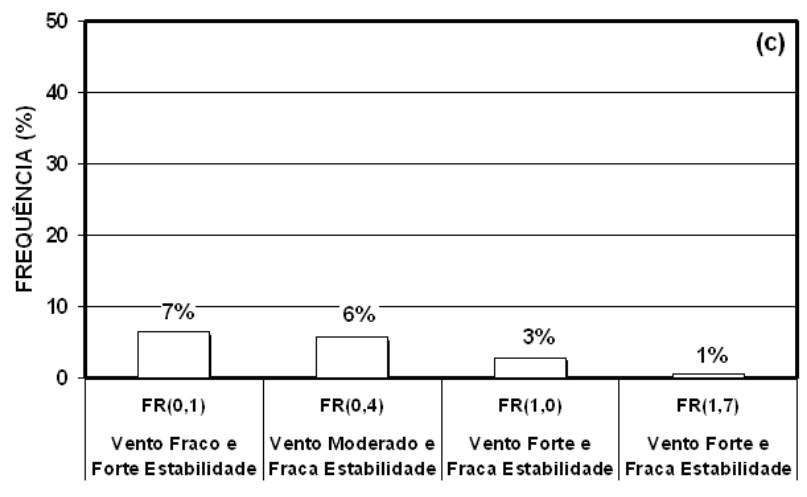

circulação da brisa marítima local. Mesmo sabendo que no período da noite ocorreu à predominância da condição estável, conforme a climatologia discutida anteriormente, as velocidades do vento máximas nestes horários contribuíram para o aumento da categoria (Figura não mostrada).

Na Figura 12 é apresentada a distribuição percentual das categorias no ciclo diário-sazonal. Observou-se que no período da madrugada, manhã e durante a noite houve as maiores ocorrências da categoria $\mathrm{F}_{\mathrm{r}}(0,1)$, exceto à tarde, onde há uma redistribuição das categorias, isso ocorre devido à influência da circulação da brisa marítima (Figura 12c). Na categoria $F_{r}$ $(0,4)$ as maiores ocorrências foram à tarde, seguida da noite, com um aumento considerável em comparação à categoria $\mathrm{F}_{\mathrm{r}}$ $(0,1)$, isso se deve ao acoplamento do regime de vento de encosta e a circulação da brisa marítima local. Vale ressaltar que na primavera há aumento significativo das outras categorias em comparação as outras estações. Na CNAAA foram identificados dois principais regimes de escoamento, que são dependentes da

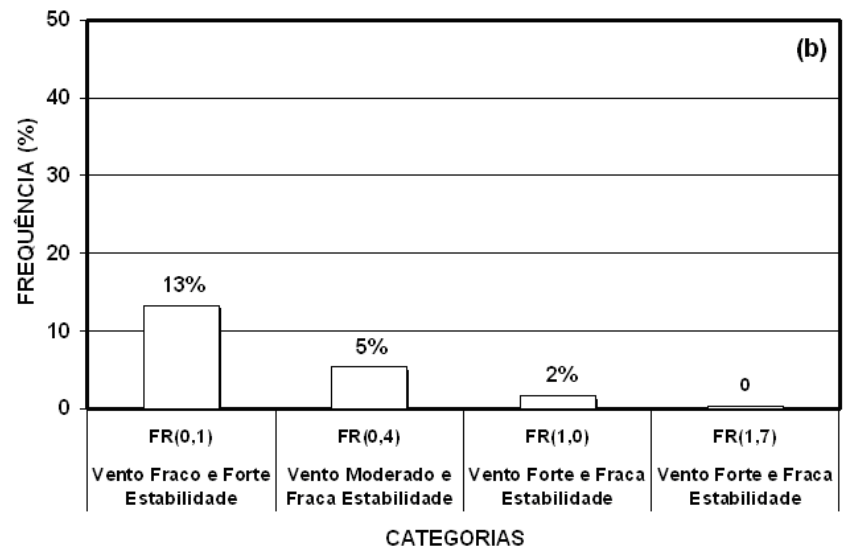



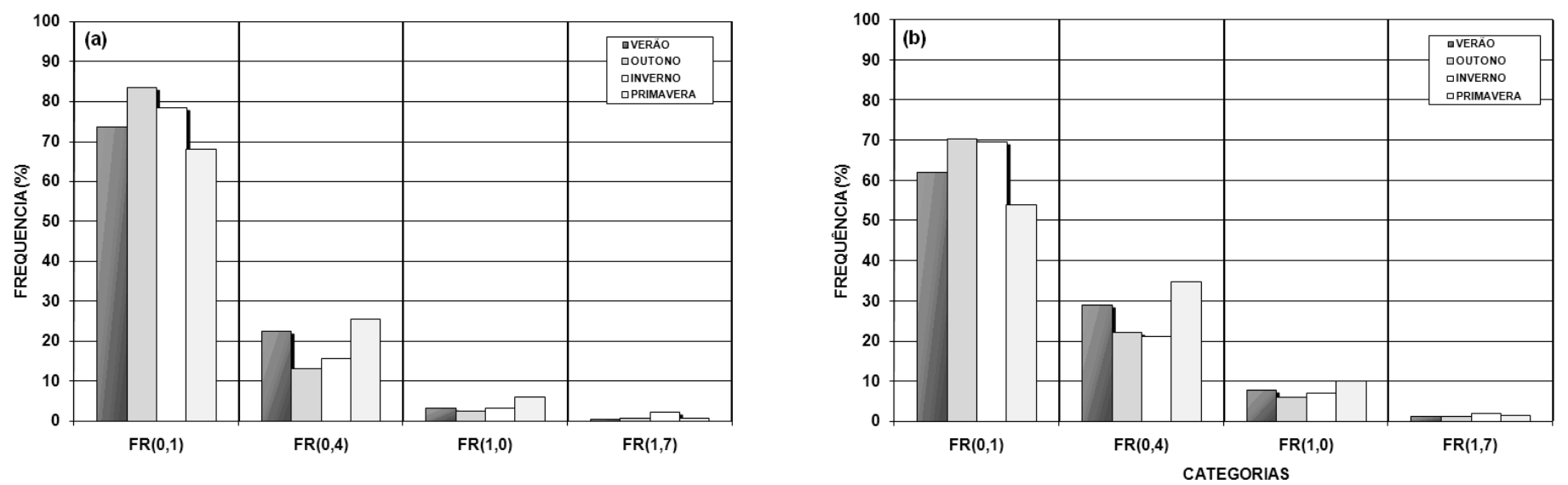

Figura 12: Freqüência (\%) do Número de Froude (100 m) sazonal - horária (a) 0-6, (b) 6-12 horas da Torre A (2002-2005). Continuação
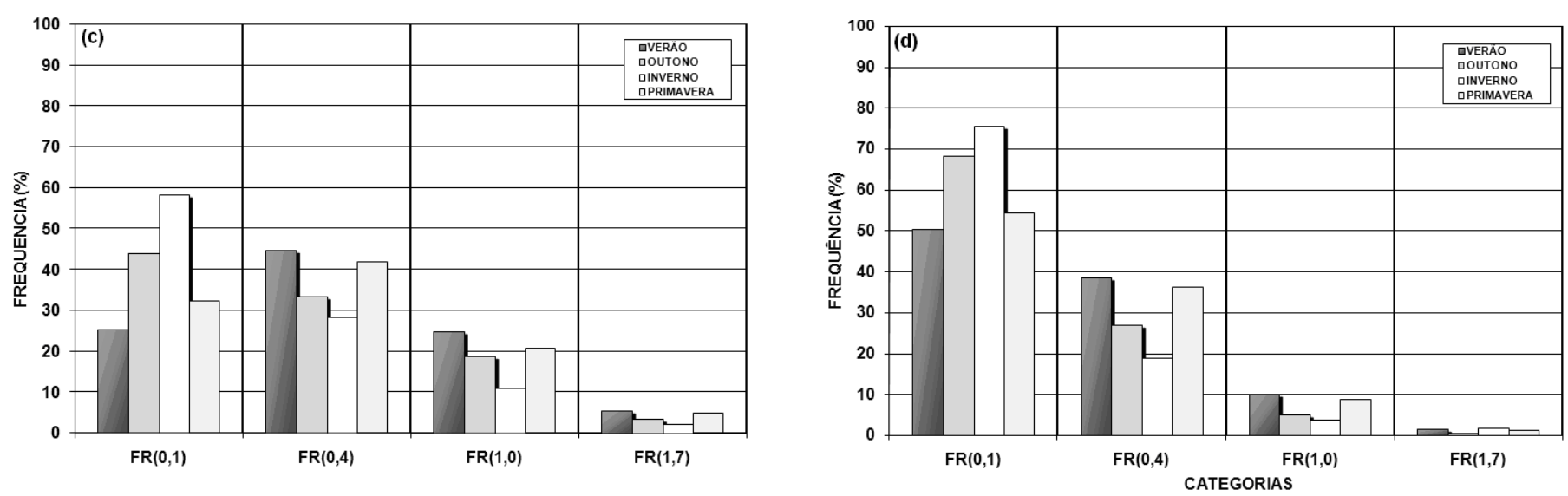

Figura 12 - Freqüência (\%) do Número de Froude (100 m) sazonal - horária (c) 12-18 e (d) 18 -24 horas da Torre A (2002-2005).

sazonalidade e dos períodos. Um refere-se ao regime de ventos fracos e forte estabilidade, que produz estagnação e o efeito de bloqueio na região $\left(F_{r}(0,1)\right)$, e outro se refere ao regime de ventos moderados e fraca estabilidade que produz alteração no padrão do escoamento, onde esse escoamento é dividido em uma parte que contorna a montanha e a outra que consegue passar sobre ela $\left(\mathrm{F}_{\mathrm{r}}(0,4)\right)$.

\section{CONCLUSÕES}

Foram identificados padrões no escoamento e na condição de estabilidade local, devido ao acoplamento das forçantes térmicas e dinâmicas atuantes na região da Central Nuclear Almirante Álvaro Alberto, Angra dos Reis - RJ.

Climatologicamente e sazonalmente a condição de estabilidade estática predomina na região, no entanto, há ocorrência de freqüências menores nas demais classes de estabilidade. Os horários preferenciais são à noite e pela madrugada, com ventos fracos a moderado nas direções $\mathrm{N}$, NNE e NNW.

No período de 2002-2005, a condição de estabilidade estática predomina na região, similar a climatologia, associada ao escoamento caracterizado por um regime de vento fraco, com forte estabilidade e ar estagnado. Apesar de ocorrerem outras categorias de menor freqüência na região, principalmente na estação da primavera.

Observa-se influência das circulações de mesoescala nas condições de estabilidade, com a brisa marítima favorecendo a condição neutra e levemente estável, enquanto que o regime de vento de encosta influencia a condição levemente estável e moderadamente estável.

A atmosfera da região apresenta baixa capacidade para a dispersão de poluentes, devido à predominância da condição estável e do regime de bloqueio.

As implicações dos resultados deste estudo necessitam ser explorados com outros parâmetros tais como, comprimento 
de Monin-Obukhov (L), velocidades de atrito ( $\mathrm{u}_{*}$ ) e convectiva $\left(\mathrm{W}_{*}\right)$, e ainda outras formulações do Número de Richardson (gradiente, gradiente geométrico e tradicional) na avaliação da estabilidade e do escoamento da CNAAA. Deve-se também, realizar as análises para $\mathrm{P}-\mathrm{G}$, dividida nos mesmos períodos diários dos demais critérios $\left(\mathrm{R}_{\mathrm{iB}}\right.$ e $\left.\mathrm{F}_{\mathrm{r}}\right)$, e não apenas no diurno e noturno, assim como incluir análise sazonal.

Sabe-se que próximo ao litoral, forma-se durante o dia uma Camada Limite Interna que invalida freqüentemente, o método vertical de temperatura para determinação das classes de estabilidade de Pasquill. No local da CNAAA, espera-se que o fenômeno da fumigação (inversão muito baixa) ocorra depois de uma noite e manhã com predominâncias de estabilidade das classes E e F. Contudo, essa situação terá permanência superior a algumas horas, quando houver a entrada da brisa marítima. Somente medidas de ar superior no local, ainda que esporádicas, poderão validar essas hipóteses para o sítio da CNAAA. É sugerido o uso de modelos de mesoescala, juntamente com os dados observacionais, para avaliação dessas hipóteses.

\section{AGRADECIMENTOS}

Os autores expressam os seus sinceros agradecimentos àqueles que foram os revisores anônimos deste artigo através de suas críticas, sugestões e correções.

Agradecem a Eletronuclear por ceder gentilmente os dados meteorológicos da CNAAA. À Comissão Nacional de Energia Nuclear (CNEN) pela concessão da bolsa de doutorado para o primeiro autor. Os autores são especialmente gratos aos pesquisadores Roosevelt Rosa (CNEN) e Reginaldo Ventura de Sá (UFRJ) na ajuda computacional.

\section{REFERÊNCIAS BIBLIOGRÁFICAS}

ARYA, S. P. Introduction to Micrometeorology. Academic Press, San Diego-USA, 310p., 2000.

BIAGIO, R. M. S. Análise Comparativa de Três Sistemas de Coeficientes de Dispersão Atmosférica na Região de Angra dos Reis. Dissertação de M.Sc., COPPE/UFRJ, Rio de Janeiro, RJ, Brasil, 235p., 1982.

CARPENTER, S. B. Principal Plume Dispersion Models: TVA Power Plants. Journal Air Polluants Control Ass. v. 21, p. 491-495, 1971.

DeMARRAIS, G. A. Atmospheric stability class determinations on a 481-meter tower in Oklahoma. Atmospheric Environment, v.12, p.1957-1964, 1978.

FRANCO, N. J. N. Aplicação de um Modelo de Trajetórias na Simulação do Transporte de Radionuclídeos na Atmosfera. Tese de D.Sc., COPPE/UFRJ, Rio de Janeiro, RJ, Brasil, 280 p., 2005.
FURNAS, C. E. Programa paraAnálise dos Dados Meteorológicos de Vento e Estabilidade Atmosférica da CNAAA - Manual do Usuário. Nota Técnica, DCSN - 0018 - 85, Jullho, p. 21, 1985.

GIFFORD, F.A. Turbulent Diffusion-Typing Schemes: A Review. Nuclear Safety, v.17, p.68-86, 1976.

GIFFORD, F.A. Use of Routine Meteorological Observations for Estimating Atmospheric Dispersion. Nuclear Safety, v.2, p. 47-51, 1961.

GOLDER, D. Relations Among Stability Parameters in the Surface Layer. Boundary Layer Meteorology, v. 3, p.47-58, 1972.

HANNA, S.R., BRIGSS, G.A., HOSKER, R. P. Handbook on Atmospheric Diffusion. $1^{\text {a }}$ ed., New York, Department of Energy, 1982, 158p.

HOLTON, J. R. An Introduction to Dynamic Meteorology. 3a ed., San Diego, Academic Press, 186p., 1992.

KAIMAL, J.C.; FINNIGAN, J.J. Atmospheric Boundary Layer Flows. Their Structure and Measurement. New York: Oxford: Oxford University Press., 289p., 1994.

LEÃO, I. L. B. Cenários Ambientais em Centrais Nucleares: Integração da Meteorologia Local com outros fatores Ambientais por meio do Sistema de Informações Geográficas. Dissertação de M. Sc., IME, Rio de Janeiro, RJ, Brasil, 158p., 1998.

LEÃO, I.L.B. Cálculo dos Fatores de difusão a monitoração da Contaminação Radioativa da Atmosfera para Angra I, II e III nas Torres Meteorológicas. Relatório - 551.5 - L432, Comissão Nacional de Energia Nuclear (CNEN), Rio de Janeiro, RJ, Brasil, 16p., 1992.

MARTANO, P., PASCHOA, A. S. Atmospheric Dispersion Modeling: the 1984 experiment in Angra dos Reis. Revista Brasileira de Física Aplicada e Instrumentação, v. 12, p.107-118, 1997.

MOHAN, M. B, SIDDIQ, T. A. Analysis of Various Schemes for the Estimation of Atmospheric Stability Classification. Atmospheric Environment, v.32, p.3775-3781, 1998.

NICOLLI, D. Análise da rosa dos ventos em Itaorna. Relatório Técnico DIN-01/82, Comissão Nacional de Energia Nuclear (CNEN), Rio de Janeiro, RJ, Brasil, 35p., 1982.

NICOLLI, D. Persistência das condições de difusão atmosférica em Angra dos Reis. Relatório Técnico DIN-01/81, Comissão Nacional de Energia Nuclear (CNEN), Rio de Janeiro, RJ, Brasil, 30p., 1981.

NICOLLI, D. Primeira campanha de experimento de difusão atmosférica na área da Central Nuclear de Angra dos Reis - análise de resultados. Relatório Técnico da Comissão Nacional de Energia Nuclear (CNEN) - n 133 p. 100, Julho, 1986.

OKE, T. R. Boundary Layer Climates. 2d ed. University Press, Cambridge, 435p., 1992. 
OLIVEIRA JÚNIOR, J. F. Estudo da Camada Limite Atmosférica na Região de Angra dos Reis Através do Modelo de Mesoescala MM5 e Dados Observacionais. Tese de D. Sc., COPPE/UFRJ, Rio de Janeiro, RJ, Brasil, 272p., 2008.

OLIVEIRA JÚNIOR, J. F., PIMENTEL, L. C. G., LANDAU, L. Avaliação da Altura da Camada Limite Atmosférica na região da Central Nuclear Almirante Álvaro Alberto sob Diferentes Forçantes Sinóticas via MM5. Ciência e Natura, v.4, p.353 - 356, 2005.

PASQUILL, F. Atmospheric Dispersion Parameters in Gaussian Plume Modelling. Part II. Possible Requirements for Change in the Turner Worbook Values. USEPA-EPA-600/4-76030b, RTP.NC 27711, p.159, 1976.

PASQUILL, F. The Estimation of the Dispersion of Windborne Material. Meteorological Magazine, v. 90, p. 33-49, 1961.

PIELKE, R. A. Mesoscale Meteorological Modeling. Academic. San Diego, 475p., 2002. SEINFIELD, J. H., PANDIS, S. N. Atmospheric Chemistry and Physics:
From Air Pollution to Climate Change. Academic. San Diego, 557p., 2000.

SLADE D. H. Meteorology and Atomic Energy. Ed. Air Resources Laboratory, 1968, 445p.

SMITH, M. E. The Forescanting of Micrometeorological Variables. Meteorological Monographs, v. 4, p. 50-55, 1951.

STULL, R. B. An Introduction to Boundary Layer Meteorology. Massachusetts: Kluwer Academic Norwell, 1988. $666 \mathrm{p}$.

STULL, R. B. Static Stability - An Update. Bulletin American Meteorological Society, v. 72, p.1521-1529, 1991

TURNER, D. B. A Difusion Model for an Urban Area. Journal Applied Meteorology, v.3, p.83-91, 1964.

TURNER, D. B. Relationships Between 24-Hours Mean Air Quality Measurements and Meteorological Factors in Nashville, Tenn. Journal Air Pollutants Control Ass., v.11, p.483-489, 1961. 